\title{
Free Radical Scavenging Activity of Essential Oil of Eugenia caryophylata from Amboina Island and Derivatives of Eugenol
}

https://doi.org/10.1515/chem-2019-0047

received October 23, 2018; accepted January 27, 2019.

\begin{abstract}
Essential oil from Eugenia caryophylata was normally used to heal many different deseaces. Various chemical compositions of essential oil distilled and steamed of Moluccas Eugenia caryophylata has been investigated by many different researchers. Even though an intensive research has been carried out of the local chemotypes, a very detail study has not been fully investigated to find out the complete chemical compounds from the plant essential oil and its content associated with their biological activities. In present paper, we assess the free radical scavenging of $E$. caryophylata collected from Moluccas islands, Indonesia. Essential oil was extracted from leaves, buds, and stems of plant by steam distillation and analyzed using GC-FID and GC-MS. The result showed that free radical activity of essential oil, main constituent and its derivatives were analized using in vitro method. Essential oil activity from stem obtained as $(0.82 \pm 0.15 \mu \mathrm{g} / \mathrm{mL})$ was higher than that from bud and leaf possessing both 1,1-diphenyl-2-picrylhydrazyl (DPPH) and (2,2'-azino-bis-3-ethylbenzthizoline-6-sulphonic acid (ABTS) radical scavenging assays by sinergism of eugenol, eugenyl acetate, $\beta$-caryophylene and humulene. The activity of isoeugenol (2) $(3.59 \pm 0.54 \mu \mathrm{M})$ and $(5.0 \pm 0.53 \mu \mathrm{M})$ scavenging DPPH and ABTS, respectively, as derivatives eugenol was higher than (3), (4) and (5). Although (6) was active originally, it was inactive after conversion of the ester. While the change of the double bond of location to conjungation structure caused more activity scavenging radicals than the starting molecule.
\end{abstract}

\footnotetext{
*Corresponding author: Hanoch Julianus Sohilait, Department of Chemistry Faculty of Mathematic and Natural Science, Pattimura University, Ambon, 97233, Indonesia, Email: nokesohilait@yahoo.com Healthy Kainama: Departement of Chemistry Education, Faculty of Training and Education, Pattimura University, Ambon, 97233, Indonesia
}

Keywords: Amboina island; free radical scavenging; isomethyl eugenol; methyl eugenol hydroxy.

\section{Introduction}

Natural product compounds, including essential oils (EOs) distilled from Eugenia caryophylata have various chemical contents depending on local distribution of the plants. There are three parts of clove tree in famous Moluccas islands of Indonesia such as buds, leaves, and stems can produce clove oil by using steam distillation. Indonesia, Tanzania, Sri Lanka, Madagascar are world largest cloveproducing countries on earth. While, India had a limited scale of clove product [1]. The primary contents of clove oil are eugenol, $\beta$-caryophylene, $\alpha$-humulene, eugenyl acetate, and humulene epoxide [2-3]. Even though there were many compounds found in clove oil closely related to geographical location, and the plant tissue, eugenol remains the primary constituent of clove oil [4-5]. In 2018 [6], Da Silva et al., found that by modifiying the molecular structure of an active subtance it can be used as an anti tumor and anti infective drug.

Eugenol, a major compound inside clove oil, is generally isolated by using a distillation process with a reduced pressure. Moreover, the eugenol hydroxyl and allyl groups can be changed to other functional groups. On the other hand, eugenol as one of phenolic compounds can easily be converted into methyl eugenol by the use of a methylation reaction of eugenol with DMS [7-8]. While another method to produce methyl eugenol is by the process of eugenol with dimehyl carbonate (DMC) with the help of Phase transfer catalyst (PTC) [9-14]. The reaction of isoeugenol with acetic anhydride forms isoeugenol acetate [15-16]. Isomerization of alkenyl-alkoxybenzenes, especially, linked to a migration process of a double bond in the alkenyl group of alkenyl-alkoxybenzenes from a not conjugated position with the benzene ring to a conjugated position with the benzene ring by the use of 


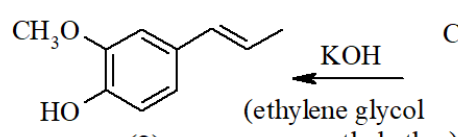

(2) monomethyl ether)<smiles>CC=Cc1ccc(OC)c(OC(C)=O)c1C(C)(C)C</smiles>

(6)<smiles>C/C=C/c1ccc(OC)c(OC)c1</smiles>

(1)
(3)<smiles>COc1ccc(CC(C)O)c(CCI)c1OC</smiles>

(4)

Scheme 1: Derivatives of Eugenol.

a base catalyst. Eugenol and methyleugenol, which have an allyl group can be converted into an isomer by using $\mathrm{KOH}$-alcoholic, or without the use of an alcoholic solvent in order to yield isoeugenol and isomethyl eugenol, respectively [17-19]. While the synthesis of secondary alcohols that changes the double bond to be a hydroxyl group shown in scheme 1 can be conducted using few types of techniques of oxymercuration-demercuration of olefin by adding mercury acetate and $\mathrm{NaBH}_{4}$ based on in situ according to ref. [20-21]. The other method to produce a secondary alcohol was by changing the allyl group of methyl eugenol through additional formic acid, and then followed by hydrolysis treatment [22].

Free radicals existance produced in plants are very important to initiate chain reactions that heal damage cells, and cause a death cell alive. In general, many deathly diseases such as cardiovascular and neurodegenerative diseases were because of damage cells. The free radicals in plants can fight against the such effects due to antioxidant subtances [23]. Eugenol as one of antioxidant compounds is powerful to fight oxidative stress for a better health. Therefore, the broad spectra of biological activities of eugenol in this research work was to find out its derivatives by chemical proceses of isomerization, subtitution and addition reactions, respectively. We present this novel work that connects between the specific compounds found in E. caryophylata from Amboina island, and its EOs.

\section{Experimental}

\subsection{Equipment}

The equipment used in this research consisted of three groups of apparatuses. The first group was from fractional distillation under reduced pressure, electric heaters, evaporators and tools of Buchii laboratory glassware. The second ones were spectroscopy instruments of Spectrophotometer PD-303S, Apel, Japan, Infra Red spectrophotometer (FTIR-8400S, Shimadzu), and ${ }^{1} \mathrm{H}-\mathrm{NMR}$ Spectrophotometer (JEOL-MY 400). Finally, Gas Chromatography 2010 Shimadzu (GC), and Mass Spectrophotometer QP 2010 Plus (MS), Shimadzu (GC-MS) were employed to identify the compounds.

\subsection{Materials}

There were bud, leaf, stem as parts of E.caryophylata taken from local garden in Amboina Island as row materials.

\subsection{The Essential Oil Isolation and Synthesis Derivatives of Eugenol}

The volatile oils of clove were obtained by conventional distillation [24]. The dried materials $(1.00 \mathrm{~kg})$ of bud, leaf $(1.00 \mathrm{~kg})$ and stem $(0.60 \mathrm{~kg})$ were treated by steam distillation for 6 hours. The composition of essential oil was analysed using GC. The isolation of eugenol (1) from stem clove oil was done by using a sodium hydroxide $(\mathrm{NaOH})$ solution to obtain sodium eugenolate, followed by acidification with $20 \%$ hydrochloric acid $(\mathrm{HCl})$, and then distilled under pressure reduction at $1200^{\circ} \mathrm{C} / 10 \mathrm{mmHg}$ yielding eugenol (1) as large as $74.09 \%[19,24]$. The spectral data corresponded with the earlier reports [17,18]. The isomerization of eugenol (1) with $\mathrm{KOH}$ in a solvent ethylene glycol monomethyl ether was refluxed at $140^{\circ} \mathrm{C}$ for 4 hours, followed by distillation under the pressure of $10 \mathrm{mmHg}$ at $120-122^{\circ} \mathrm{C}$ yielding isoeugenol (2) with the content of $69.72 \%$ [18]. The methylation of eugenol (1) was carried out using DMS at the $103^{\circ} \mathrm{C}$ for 90 minutes, followed by distilling under pressure at $140^{\circ} \mathrm{C} / 20 \mathrm{mmHg}$ which yielded methyl eugenol with the amount of $62.08 \%$ [8,22]. 
The spectral data was fitted with that given in previous reports $[8,16,17,22]$. The isomerization of methyleugenol (3) with $\mathrm{KOH}$, and without any solvent at the $140^{\circ} \mathrm{C}$ for 4 hours yields isomethyleugenol (4) (66.68\%). The compound was then identified using GC yielding cis-isomethyleugenol (9.80\%) and trans-isomethyleugenol (90.20\%) [16-17]. The oxymercuration-demercuration of methyl eugenol (3) was carried out with $\mathrm{Hg}(\mathrm{OAc})_{2}-\mathrm{NaBH}_{4}$, followed by distillation process with reduced pressure reduction at $146^{\circ} \mathrm{C} / 10 \mathrm{mmHg}$ to obtain methyleugenyl alcohol (5) (78.03\%) [20-21]. The spectral data was comparable with that in ref. $[8,22]$. The isoeugenyl acetate was synthesized from isoeugenol (2) and acetate anhydrous using sodium acetate as a catalyst. The mixture was refluxed at $120^{\circ} \mathrm{C}$ for $90 \mathrm{~min}$, followed by recrystallization in methanol to obtain isoeugenyl acetate (6) with yield as high as $63.08 \%$ at b.p $65^{\circ} \mathrm{C}[15]$.

\subsection{DPPH and ABTS Free Radical Scavenging Assays}

\subsubsection{DPPH free radical scavenging assay}

The DPPH activity was investigated with the method described in Ref. [25]. The test sample $(10 \mathrm{mg})$ was dissolved in $1 \mathrm{~mL}$ methanol. The reaction mixture consisted of $1 \mathrm{~mL}$ of DPPH $6 \times 10^{-5} \mathrm{M}$ and $33 \mu \mathrm{L}$ sample solution in methanol. After $20 \mathrm{~min}$ incubation at $37^{\circ} \mathrm{C}$, the absorbance values of the sample caused by the reaction in the prepared mixture were measured at a wavelength of $515 \mathrm{~nm}$ using a spectrophotometer PD-303S, Apel, Japan. The blank samples comprised of $33 \mathrm{~mL}$ of methanol in a DPPH solution was also measured at the same wavelength. The experiment was performed in triplicate. While the percentage of inhibition was calculated using equation:

$$
\text { Percentage of inhibition }=-\mathrm{Abs}_{\text {test }} / \mathrm{Abs}_{\text {control }} \times 100
$$

In Eq. (1), the $\mathrm{Abs}_{\text {control }}$ was absorbance of blank, while the $\mathrm{Abs}_{\text {test }}$ were absorbance of all the samples. A lower absorbance in the sample was indicated as a higher DPPH scavenging activity. The concentration dependence of $\mathrm{IC}_{50}$ value was determined from EOs and its derivatives prepared with the DPPH radical to $50 \%$ of the control. Ascorbic acid was used as a standard.

\subsubsection{ABTS free radical scavenging assay}

The ABTS radical scavenging assay was carried out according to the method described by Fitriana et al.
[26]. By oxidating ABTS with potasium persulfate, the ABTS radial was obtained. In order to form ABTS cation solution, $5 \mathrm{~mL}$ ABTS $(7 \mathrm{~mm})$ was mixed with $100 \mu \mathrm{L}$ of potassium persulphate, and then incubated for 12 hours. Furthermore, the working solution was prepared with a certain amount of the former solution following by adding the phosphate buffer saline solution until the absorbance as large as $(0.70 \pm 0.001)$ at $734 \mathrm{~nm}$. The freshly prepared working solution was then kept in the dark for 30 minutes. A volume of $1 \mathrm{~mL}$ of different concentrations of plant extract was mixed thoroughly with $1 \mathrm{~mL}$ of working solution, and kept in the dark for 10 minutes. The absorbance of the test sample was measured at the same wave length of 734 $\mathrm{nm}$. of the control sample. The percentages of inhibition were calculated using Eq. (1) in which the $\mathrm{Abs}_{\text {control }}$ was absorbance of blank, while the $\mathrm{Abs}_{\text {test }}$ were absorbance of all the samples. A lower absorbance in the sample was indicated as a higher ABTS scavenging activity. The concentration dependence of $\mathrm{IC}_{50}$ value was determined from EOs and its derivatives prepared with the ABTS radical to $50 \%$ of the control. Ascorbic acid was used as a standard.

Ethical approval: The conducted research is not related to either human or animal use.

\section{Results and Discussion}

\subsection{Chemistry}

The starting material eugenol (1) was isolated from clove stem oil. The isomerization of (1) with $\mathrm{KOH}$ in ethylene glycol monomethyl ether produced (2). Methylation of eugenol (1) with dimethyl sulphate (DMS) produces methyleugenol (3) and isomerization of (3) with $\mathrm{KOH}$ without solvent produced isomethyleugenol (4). Oxymercuration-demercuration of methyleugenol with $\mathrm{Hg}(\mathrm{OAc})_{2}-\mathrm{NaBH}_{4}$, produced methyleugenyl alcohol (5) and esterification of (2) with anhydrous acetate produces isoeugenyl acetate (6) as shown in Scheme 1.

\subsection{Free Radical Scavenging Activities}

To evaluate the antioxidant properties of essential oil, eugenol and derivatives, two methods of DPPH and ABTS were employed. The possitive control used in this research was ascorbic acid. The inhibition concentration, $\mathrm{IC}_{50}$ was measured for the antioxidant activity and the compounds, respectively. The results of scavenging activities are 


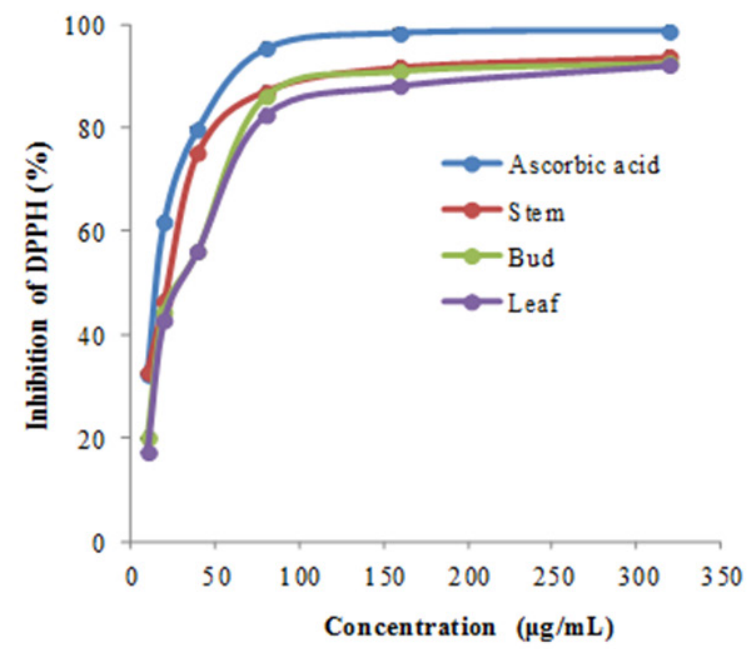

A

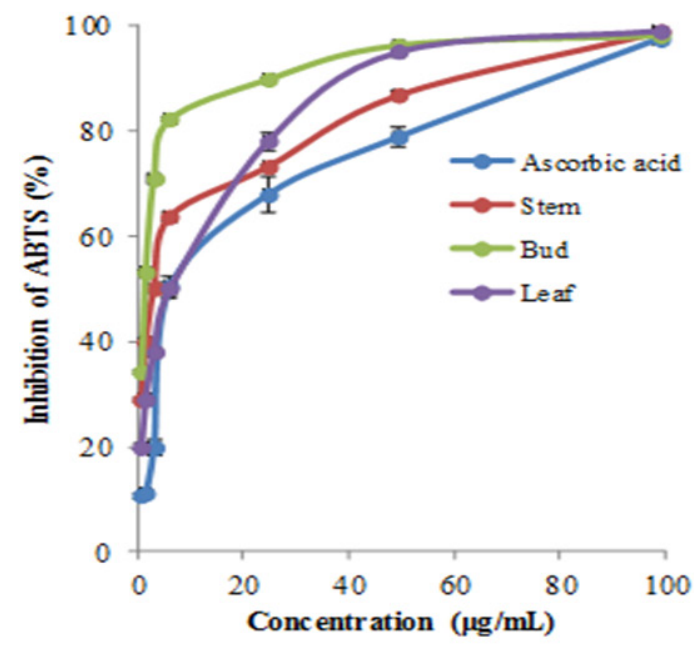

$\mathrm{B}$

Figure 1: Scavenging effect of different essential oils and ascorbic acid (A) DPPH, (B) ABTS assays at concentration $319.45 \mu \mathrm{g} / \mathrm{mL}$ and 99.00 $\mu \mathrm{g} / \mathrm{mL}$. Mean values are significantly average $\mathrm{SD} \pm \mathrm{n}=3$.

Table 1: $I C_{50}$ value free radical scavenging of essential oil.

\begin{tabular}{lll}
\hline & DPPH $(\mu \mathrm{g} / \mathrm{mL})$ & ABTS $(\mu \mathrm{g} / \mathrm{mL})$ \\
\hline Essential oil from stem (EOS) & $0.82 \pm 0.15$ & $0.81 \pm 0.16$ \\
Essential oil from bud (EOB) & $1.18 \pm 0.56$ & $0.54 \pm 0.77$ \\
Essential oil from leaf (EOL) & $1.16 \pm 0.74$ & $0.66 \pm 0.67$ \\
Ascorbic acid (positive control) & $1.38 \pm 0.65$ & $0.74 \pm 0.54$ \\
\hline
\end{tabular}

listed in Table 1. The sample amount needed in order to decrease the absorption of DPPH and ABTS by $50 \%$ was then calculated graphically by plotting $\%$ of inhibition against the concentration in $\mu \mathrm{g} / \mathrm{mL}$.

The free radical scavenging activity of the essential oil on the DPPH scavenging was observed at $319.45 \mu \mathrm{g} /$ $\mathrm{mL}$ to $9.98 \mu \mathrm{g} / \mathrm{mL}$ concentration. All of the essential oils, regardless of distilation steam method, showed DPPH scavenging activity that increased in a concentration dependent manner. As shown in Figure 1A, all the essential oils, including the reference ascorbic acid (AA), exhibit intense DPPH radical scavenging activity at low concentration $9.98 \mu \mathrm{g} / \mathrm{mL}$. The percentage of inhibition of DPPH from stem essential oil was high $(99.00 \pm 1.05 \%)$, followed by bud $(98.80 \pm 0.96 \%)$, and leaf $(98.10 \pm 0.76 \%)$. The value of IC $_{50}$ value showing high activity of DPPH was (0.82 \pm 0.15$),(1.18 \pm 0.56)$ and $(1.16 \pm 0.65)$, for stem, bud, leaf, respectively.

As shown in Figure 1B, the free radical scavenging activity of the essential oil on the ABTS scavenging were observed at concentration of $99.00 \mu \mathrm{g} / \mathrm{mL}$ to $0.77 \mu \mathrm{g} /$
$\mathrm{mL}$. The percentage of inhibition of ABTS from bud essential oil was high $(93.53 \pm 0.68 \%)$, followed by leaf $(92.33 \pm 0.34 \%)$ and stem $(91.94 \pm 0.68 \%)$. The value of $\mathrm{IC}_{50}$ showing high activity of ABTS was $(0.54 \pm 0.77),(0.66 \pm 0.67)$ and $(0.81 \pm 0.16)$, for bud, leaf, stem, respectively.

The higher antioxidant activity of oil of E. caryophylata EOS could be related to the synergistic property associated with the high content of eugenol (97.75\%) with other constituents viz., $\beta$-caryophylene $(0.90 \%)$, eugenyl acetate $(0.76 \%)$ and caryophylene oxide $(0.59 \%)$ reported previously (Sohilait et al, 2018). The presence of eugenyl acetate (20.93\%) synergic with eugenol (75.30\%), $\beta$-caryophylene (3.0\%), humulene $(0.37 \%)$ and caryophylene oxide $(0.40 \%)$ in EOB makes its ABTS activity higher than EOL's. On the other hand, the absence of eugenyl acetate in EOB could cause higher antioxidant activity of scavenging ABTS than EOL's. Humulene in EOS had no indicator of the presence of antioxidant activity, which may be due to the absence of participating electron delocalization group or protons. The presence of $\beta$-caryophylene, caryophylene oxide and humulene from the EOs could show no effect of antioxidant activity [27-28]. The essential oils of eugenol were compared to a known synthetic antioxidant ascorbic acid (Table 1). The oil of E. caryophylata showed better antioxidant property than pure eugenol. The important facts found are the nonspecific responses and synergistic effects of the compounds from essential oil. For this reason, a bioassay-direct fractionation of an active extract was not always contribute to the isolation of active compouds. An 


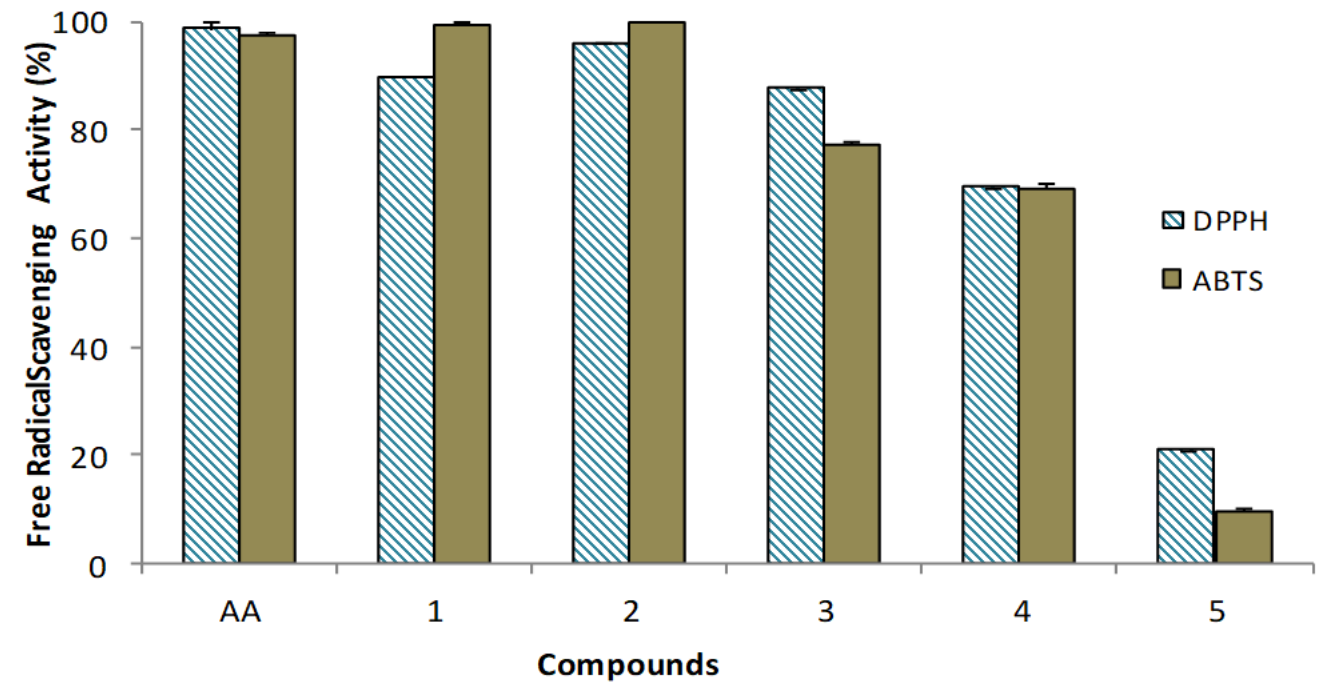

Figure 2: Inhibition of eugenol and it's derivatives at DPPH and ABTS. Values were performed in triplicate and represented as mean \pm SD. Abbreviation: AA, ascorbic acid.

Table 2: Radical scavenging activity of eugenol and it's derivatives.

\begin{tabular}{lll}
\hline Compounds & DPPH $(\mu \mathrm{M})$ & ABTS $(\mu \mathrm{M})$ \\
\hline Eugenol (1) & $6.34 \pm 0.79$ & $6.76 \pm 3.13$ \\
Isoeugenol (2) & $3.59 \pm 0.54$ & $5.0 \pm 0.53$ \\
Methyl eugenol (3) & $7.80 \pm 1.34$ & $6.79 \pm 1.05$ \\
Isomethyl eugenol (4) & $8.53 \pm 1.28$ & $9.88 \pm 0.86$ \\
Methyl eugenyl hydroxy (5) & $>100$ & $>100$ \\
Isoeugenyl acetate (6) & - & - \\
Ascorbic acid (positive control) & $4.71 \pm 1.05$ & $4.65 \pm 1.64$ \\
\hline
\end{tabular}

apparent loss of activity on separation of synergistically acting components of low part potency cannot be easily distinguished from the loss of activity resulting from the chemical changes induced by particular isolation technique. In this work, we summarized that stem, bud and leaf of E.caryophylata from Amboina Island can be used as a source for use as a food additive, preservative, and as an antiseptic.

The free radical scavenging activity of the eugenol was then measured using a DPPH assay reported in the literature [6]. When the scavenging activity of each compound was quantified by the colorization of DPPH at $515 \mathrm{~nm}$ after 20 min-incubation at $37^{\circ} \mathrm{C}$, compound isoeugenol exhibited radical scavenging activity, even though its activity was higher than that of derivatives compounds (Table 2). Secondary alcohols generally have little scavenging effects. The result showed that isoeugenyl acetate 6 has no activity, indicating that the radical scavenging effect was caused by the hydroxyl attack of the benzene ring of compound (1).

The antioxidant activity of eugenol derivatives was investigated with DPPH and ABTS. One of the best methods for screening the antioxidant activity of a substance was radical scavenging activity. The capture capability of free radicals induced by eugenol derivatives (3-5) against $\mathrm{DPPH}$ and $\mathrm{ABTS}$ were analized in parameter $\mathrm{IC}_{50}$, which represents the concentration required to capture $50 \%$ of the radicals in the medium. Phenolic compounds, such as eugenol, have the ability of transfering electron or hydrogen atoms by neutralizing free radicals which can block the oxidative process [29-30]. The results depicted in Table 2 showed that all the derivatives (3-6) presented higher $\mathrm{IC}_{50}$ than eugenol. Such cause was due to the structural modification resulted in subtances with lower DPPH scavenging effects. Compound (2) was produced by isomerization of compund (1).

The result of DPPH and ABS assays for compound (1) showed higher antioxidant properties compared to that of compounds (3-6). The highest antioxidant properties in inhibition ABTS of compound (2) is possibly due to the resonance with the aromatic ring to produce the stabilization of phenoxyl radicals. On other hand, chemical modification of the hydroxyl group resulted in subtances with lower antioxidant effects. Compound (6) was fabricated by an esterification reaction on the hydroxyl group, and resulted in a strong reduction in antioxidant activity to be an inactive compound [23,3132]. The secondary alcohol compound was produced by the oxymercuration-demercuration reaction of methyl 
eugenol, and is also low in antioxidant activity. In a particular manner of eugenol, the relationship between the hydroxyl group and the antioxidant action was observed in compound (2), in which this presented $\mathrm{IC}_{50}$ value of ABTS inhibition is lower than eugenol.

\section{Conclusions}

The results of both free radical scavenging assays demonstrated that structural modifications in the eugenol molecule produced a reduction in antioxidant activity. Compounds (1) and (2) have the greatest activity as free radical scavengers because of the existance of hydroxyl group in the aromatic ring related to the essential of antioxidant activity.

Acknowledgement: The authors are thankful to the Mininstry Research, Technology and Higher Education,Indonesia for financial support under Excellent Research Grant in 2018.

Conflict of interest: Authors declare that there is no conflict of interest among.

\section{References}

[1] Thankumari C.K., Shivaraman K., Kandianum K et al., Bud and leaf essential oil composition of Syzygium aromaticum from India and Madagascar J. Spices Arom Crops, 1994, 3, 105-123.

[2] Jirovetz L., Buchbauer G., Stoilova I et al., Chemical composition and antioxidant properties of clove leaf essential oil, J. Agric. Food chem., 2006, 54, 6303- 6307.

[3] Gupta M., Singh D., Gularia P et al., GCMS analysis and identifications of chemical constituents of Syzigium aromaticum, Brassica compestris and cow ghee, J. Chem. Pharm. Res., 2015, 7(1), 568-572.

[4] Srivastava A.K., Srivastava S.K., Syamsudar K.V., Bud and leaf essential oil composition of Syzygium aromaticum from India and Madagascar, Flavour Frag. J., 2005, 20, 51-53.

[5] Kumar A., Shukla R., Singh P et al., Chemical composition, antifungal and antiaflatoxigenic activities of Ocimum sanctum L. essential oil and its safety assessment as plant based antimicrobial, Food and Chemical Toxicology, 2010, 48 , 539543.

[6] Da Silva F.F.M., Monte F.J.Q., de Lemos T.L.G et al., Eugenol derivatives: synthesis, characterization, and evaluation of antibacterial and antooxidant activities, Chemistry Central Journal, 2018, 12, 34-42.

[7] Guenther E., The Essential Oils Vol. II IV B, Universitas Indonesia Publishing, Jakarta, 1990.
[8] Sohilait H.J., Sastrohamidjojo H., Sabirin M., et al., Synthesis of analog L- $\alpha$-methyl DOPA from eugenol, Indo. J. Chem., 2005, 5(3), 198-202.

[9] Lamoureux G., Agüero Ch., A comparison of several modern alkylating agents, Arkivoc, 2009, 1, 251-264

[10] Tundo P., New developments in dimethyl carbonate chemistry, Pure Appl. Chem., 2001, 73, 7, 1117-24.

[11] Ono Y., Dimethyl carbonate for environmentally benign reactions, Pure and Appl. Chem., 1996, 68(2), 367-375.

[12] Ouk S., Thiebaud S., Borredon E., et al., $O$-Methylation of phenolic compounds with dimethyl carbonate under solid/ liquid phase transfer system, Tetrahedron Letters, 2002, 43, 2661-2663

[13] Wen-Chung S.W.Ch., Dell St., Repic 0.,1,8-Diazabicyclo[5.4.0] undec-7-ene (DBU) and Microwave-Accelerated Green Chemistry in Methylation of Phenols, Indoles, and Benzimidazoles with Dimethyl Carbonate, Organic Letter, 2001, 3(26), 4279-4281

[14] Tundo P. and Selva M., The Chemistry of Dimethyl Carbonate Carbonate, Acc. Chem. Res. 2002, 35, 706-716.

[15] Lampman G.M., Sharpe S.D., A Phase Transfer Catalyzed Permanganate Oxidation. J. Chem. Educ., 1983, 60, 503-504.

[16] Xuan Th, Luu Th., Lam T. et al., Fast and Green MicrowaveAssisted Conversion of .Essential Oil Allylbenzenes into the Corresponding Aldehydes via Alkene Isomerization and Subsequent Potassium Permanganate Promoted Oxidative Alkene Group Cleavage, Moleecules, 2009, 14, 3411-3424

[17] Nagase Ts., Suzukamo G, Fukao M, Isomerization of alkenylalkoxybenzenes, US patent 3,852,305, Dec, 3, 1974.

[18] Baby Ch., Microwave Isomerization of Safrole and Eugenol., Syn. Comm.,1977, 27(24), 4335-4340.

[19] Sohilait M.R, Sohilait H.J, Francina E, Synthesis of 3,4-methyleedioxy isoamyl cinnamic as the sunscreen compound from culilawan oil, Ind. J. Chem. Res., 2013, 1, 1-5.

[20] Brown H.C., Geoghegen J.P.J., The OxymercurationDemercuration of Representative Olefins in an Aqueous System. A Convenient Mild Procedure for Markonikov Hydration of the Carbon-Carbon Double Bond, J.Org.Chem, 1970, 6, 18441850.

[21] Brown, H.C., Lynch, G.J., Oxymercuration-Demercuration of Methoxy, Hydroxy and Acetoxy-Substitued Alkenes, J. Org. Chem., 1981, 6(3), 531-538.

[22] Sohilait, H. J., Sastrohamidjojo, H., Sabirin, M et al., Synthesis of Secondary Alcohol Compounds from Methyleugenol, Indo. J. Chem., 2003, 3(3), $176-178$

[23] Wang J., Xia F., Wen-Bin J et al., Efficient synthesis and antioxidant activities of $\mathrm{N}$-heterocyclyl substituted Coenzyme Q analogues, Bio-Organic Chem., 2016, 68, 214-218.

[24] Sohilait H.J, Kainama H., GC/GC-MS Analysis, Isolation and Identification of Bark Essential Oil Components from Cinnamomum culilawan, Blume, Am. J. App. Chem., 2016; 4(4), 157- 160

[25] Singh R.S.G., Negi P.S., Radha C., J. of functional Foods., Phenolic composition, antioxidant and antimicrobial activities of free and bound phenolic extracts of Moringa oleifera seed flour, J. of functional Foods, 2013, 5, 1883-1891.

[26] Fitriana W., Ersam, T., Koniyoshi S et al.,Antioxidant Activity of Moringa oleifera extracts, Indones. J. Chem., 2016, 16, 297301. 
[27] Hammami S., Mokni R.E., Faidi K et al., Chemical composition and antioxidant activity of essential oil from aerial parts of Teucrium flavum L. subsp. flavum growing spontaneously in Tunisia, Nat. Prod. Res., 2015, 29(24), 2336-2340.

[28] Cote H., Boucher M., Pichette A et al., Anti-Inflammatory, Antioxidant, Antibiotic, and Cytotoxic Activities of Tanacetum vulgare L. Essential Oil and Its Constituents, Medicines, 2017, 4(2), 34-43.

[29] Hindalgo M.E., Rosa C., Antioxidant capacity of eugenol derivatives, Quim Nova, 2009, 32(6), 1467- 1470.

[30] Findik E., Ceylan M, Elmastas M., Isoeugenol-based novel potent antioxidants: Chemistry Synthesis and reactivity, Eur. J. of Med., 2011, 46, 4618-4624.

[31] Baroso MR., Ramalhosa M.J., Alves R.C et al., Total antioxidant capacity of plant infusions: Assessment using electrochemical DNAbased biosensor and spectrophotometric methods, Food control., 2016, 68, 153-161.

[32] Lasha-Benamrouchea S., Madania K., Phenolic contents and antioxidant activity of orange varieties(Citrus sinensis L. and Citrus aurantium L.) cultivated in Algeria: Peels and leaves, Industrial Corps and prod., 2013, 50, 723- 730. 